\title{
Urgences
}

\section{Mr. Solo (extraits)}

\section{Olivier Cadiot}

Numéro 33, octobre 1991

Poésies parallèles : France - Québec

URI : https://id.erudit.org/iderudit/025669ar

DOI : https://doi.org/10.7202/025669ar

Aller au sommaire du numéro

Éditeur(s)

Urgences

ISSN

0226-9554 (imprimé)

1927-3924 (numérique)

Découvrir la revue

Citer ce document

Cadiot, O. (1991). Mr. Solo (extraits). Urgences, (33).

https://doi.org/10.7202/025669ar

Ce document est protégé par la loi sur le droit d'auteur. L'utilisation des services d'Érudit (y compris la reproduction) est assujettie à sa politique d'utilisation que vous pouvez consulter en ligne.

https://apropos.erudit.org/fr/usagers/politique-dutilisation/
Cet article est diffusé et préservé par Érudit.

Érudit est un consortium interuniversitaire sans but lucratif composé de l’Université de Montréal, l'Université Laval et l'Université du Québec à Montréal. Il a pour mission la promotion et la valorisation de la recherche. https://www.erudit.org/fr/ 


\section{Olivier Cadiot}

\section{Louky Bersianik}




\section{Mr. Solo (extraits)}

Olivier Cadiot

C'est ainsi,

et ce sera comme ça mais oui

(lisez: je ne vous dis rien sur le truc)

Bien. Et sinon j'espère j'espère que ça va bien.

Je suis si tête-en-l'air souvent que j'oubliais des salutations au chien bleu

l'été il doit courir!

Ça doit être quelque chose à voir

Signé votre -

Suite et fin,

j'ajoute que la saison a été excellente

pour nous tous et de façon inespérée

Voilà une bonne façon d'envisager les choses enfin

on ne dira pas que je ne suis pas un bon garçon

Ah la la!

Merci pour le chapeau

Je vais pouvoir faire des élégances ce n'est pas qu'ici soit

l'idéal

mais il y a des petits moments où c'est permis

je voudrais tant construire une maquette

une chose en bois ou en plastique

Pensez-y

(on m'a toujours dit que c'était bon pour moi)

hé hé hé

Chère

ne viens pas la prochaine fois sans apporter ce que tu sais le ***

Ah non mais il ne faut pas oublier ses promesses

Donner c'est donner reprendre c'est voler

et ainsi de suite pour tout.

Chère et chère,

Tout à vous pour ses fêtes si cruelles

on mangera du chou je vous vois d'ici 
avec le meuble chinois et tous ces rubans

il n'y a qu'a fermer les yeux pour y être

Signé : L'Exilé de l'Intérieur

Cher

le fond de l'âme n'est point réellement distingué de ses puissances

Prenez-en de la graine

sinon, même jour même heure

On remettra ça hein? Bien à vous fidèlement, la main.

Il fait beau

il fait extrêmement beau

Oui, il faut bien dire: Seigneur, vous m'avez vue

attachée à vous nuire,

sinon, on ne comprend plus qui fait quoi.

Et si vous avez d'autres questions de ce type,

n'hésitez pas.

Serviteur,

***

Dieu soit loué j'ai reçu le colis

excellent le pigeon

et le sucré

C'est l'année qui commence en quatrième vitesse

Quant à la neige (n'en parlons pas)

Ki-ri-ki-ki

Le five-o'clock bat son plein

je ne te dirais pas qu'on se fend la pipe

mais ça a du chien (tenue de soirée, musique, etc.)

Miss Truc a des grosses miches

m'étonnerait pas que je me la mette un de ces jours

au bon moment

donnerai des détails sur la mémère

La paire de seins etc.

je file. Ca vient de sonner.

Ton chéri.

Jeudi (le jour de la sirène)

je suis dans le plâtre

t'imagines! 
arraché l'épaule avec le recul

du flingue. Pool!

et crac mon vieux c'est moi le pigeon

hi hi hi

Ça y est Victoire gagné $9 \mathrm{~h}$ et quart je lui ai foutu ma main dans la culotte

pendant au moins vingt minutes

Alleluia

t'aurais vu la bête c'est à peine croyable

Non je te jure le morceau promis juré

impossible de faire mieux

Cher vieux,

ce matin

je me suis arraché tous les poils des oreilles

un d un

intéressant, non?

Et Bijou, elle fait toujours le maximum?

Raconte. Ici on manque surtout d'informations.

Bien à toi.

Lu de la littérature de pain d'épice

- gingerbreadliterature comme ils disent ici -

toute la journée

On m'a dit qu'au début c'était comme ça et après changement de régime

genre violence si tu vois ce que je veux dire

Gooood mooooorning Sir

Mais va pas chercher des problèmes

là où il n'y en a pas (il est mignon le chien-il est mignon le chien-le chien-chien oh ce chien oh ce chien oh le chien)

J'espère que de ton côté ça va,

Stop et à bientôt signé

l'étrangleur qui t'aime

Lu:

* Jai reçu trois petits cercueils, dix lettres de faire-part, au moins vingt lettres de menace, deux couteaux à cran d'arrêt, une petite grenade [...] et cinquante grammes de cyanure... on pense à moi dans les ténèbres * 
Ça y est j'ai crevé ma haine (lundi)

Sûr

et doit-on penser que c'est irréparable si c'est dit

comme on dit c'est dit c'est dit (à partir de la sonnerie:

Dong!... je ne te parle plus gnagnagna)

réponds vite à ça.

Je suis passé par la bande

quand au sujet qui $m$ '(nous) intéresse

Express, mon vieux: direct au ciel

et bien envoyé

bien à toi, ton ${ }^{* * *}$

Je t'envoie un nouveau poème mmmagnifique (C Bibi

(j'en ai d'autres en réserve, if):

$\mathrm{Pi}$, pi, pi, de big, big? ou peut-être «pipi " (pee-pee)*

Oiseau d'eau/Os de gibier/Aiguille de pin**

Galy-Galy - Gaddy-Gaddy-Girlie-Girlie

P.S. À lire en boucle avec des cris.

Affectueusement

Vendredi. Il m'a dit que la transmutation

Va-ge-ra-ma-ga-nia (?)

c'est directement réel

De: va-ga-ga (voir)

jusqu'à: la-na chemin, il n'y a rien à faire

pof (comme une feuille de papier blanc)

et c'est là

et c'est là

où c'est réel (et il ajoute: c'est formidable) pile!

Cher -

N'oubliez pas votre fils et même si ce n'est pas une véritable détention

j'ai joué dans:

1. David reconnu Roi d'***

2. Le Temple de la Fortune

* De noir, obscur, opposé à la lumière.

** Maman maman jonquille papa jonquille maman serviette (?) os poulet oie cendrée/oie cendrée/où vais-je aller me promener? piripipi piripipi 
80

3. Le Mort imaginaire.

Oui oui oui.

Ça donne un rayonnement filial rétroactif non?

Cette soudaine gloire, hé hé hé

Ma non tropo

hein?

Je vous jure qu'ici ça marche à la baguette

je suis enfermé

Un deux et au boulot

Venez me chercher si possible je vous prie oh votre dévoué - 